\title{
A New Design of Vibration Absorber for Periodic Excitation
}

\author{
Shyh-Chin Huang and Kao-An Lin \\ Mechanical Engineering, Ming Chi University of Technology, No. 84, Gongzhuan Road Taishan New Taipei City 24301, Taiwan \\ Correspondence should be addressed to Shyh-Chin Huang; schuang@mail.mcut.edu.tw
}

Received 26 February 2013; Revised 12 January 2014; Accepted 5 February 2014; Published 25 February 2014

Academic Editor: Jeong-Hoi Koo

Copyright (C) 2014 S.-C. Huang and K.-A. Lin. This is an open access article distributed under the Creative Commons Attribution License, which permits unrestricted use, distribution, and reproduction in any medium, provided the original work is properly cited.

\begin{abstract}
The authors designed a novel type of dynamic vibration absorber, called periodic vibration absorber (PVA), for mechanical systems subjected to periodic excitation. Since the periodic rather than single harmonic excitation is the most occurring case in mechanical systems, the design of PVA is hence of engineering significance. The PVA designed in this paper is composed of a dual-beam interconnected with a discrete spring in between. By appropriately choosing the design parameters, the PVA can be of resonance frequencies in integer multiples of the base frequency such that the PVA can absorb significant amount of higher harmonics in addition to the base harmonic. The designed PVA was first experimentally verified for its resonance frequencies. The PVA implemented onto a mechanical system was then tested for its absorption ability. From both tests, satisfying agreement between experiments and numerical calculations has been obtained. The sensitivities of the design variables, such as the discrete spring's stiffness and location, were discussed as well. The parameters' sensitivities provided us with the PVA's adjustable room for excitation frequency's mismatch. Numerical results showed that within $3 \%$ of frequency mismatch, the PVA still performed better than a single DVA via adjusting the spring's constant and location. All the results proved that the novel type of PVA could be a very effective device for vibration reduction of mechanical systems subjected to periodic excitation.
\end{abstract}

\section{Introduction}

Dynamic vibration absorber (DVA), also known as tuned mass damper (TMD) [1], has been proven to be a useful device for mechanical vibration attenuation. A conventional DVA, composed of a spring-mass-damper (SMD), is mostly mounted to a primary structure, as shown in Figure 1(a) [2], to absorb the vibration of one single (tonal) frequency. The fundamental design of an SMD can be seen from many vibration textbooks and is not addressed here. The more elaborate works on SMD fall into the category of damper design. Brock [3] derived an optimum Lanchester damper. Ozer and Royston [4] extended Den Hartog's method to multi-DOF structure and derived the optimal dampers and mounting locations. They further employed Sherman-Morrison matrix inversion formula to calculate the optimal parameters for a damped multi-DOF absorber system [5]. Ren [6] introduced the so-called ground-hook DVA as shown in Figure 1(b). Of the same mass ratio and under harmonic excitation, the ground-hook DVA appeared to have better absorption than the traditional one. Wong and Cheung, similarly, concluded that the ground-hook DVA's vibration suppression is superior to the traditional one particularly when the excitation comes from the ground motion [7].

In order to enhance the DVA's absorption ability, numerous papers have been aimed at different research aspects, such as control rules derivation, structure's properties variation, special material and different DVA's combination. Details of these researches may be referenced to Sun et al. [8], where they surveyed the gradual development of the passive, adaptive, and active tuned vibration absorber. Chen and $\mathrm{Xu}$ [9] discussed a DVA comprised of not only mass-spring-viscous damper but feedback control force to suppress broadband vibration and their results showed that the response had been reduced by $90 \%$. Burdisso and Heilmann [10] developed a hybrid DVA for vibration control as shown in Figure 1(c). The DVA comprised two reaction masses and in between there was a passive/semiactive/active damper. This hybrid DVA has been proven to have better suppression effect than an ordinary SMD, particularly for broadband vibration. 


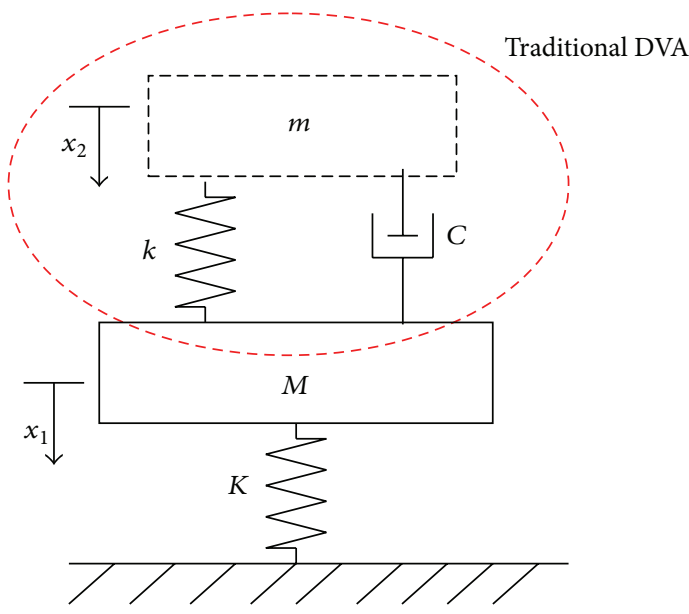

(a)

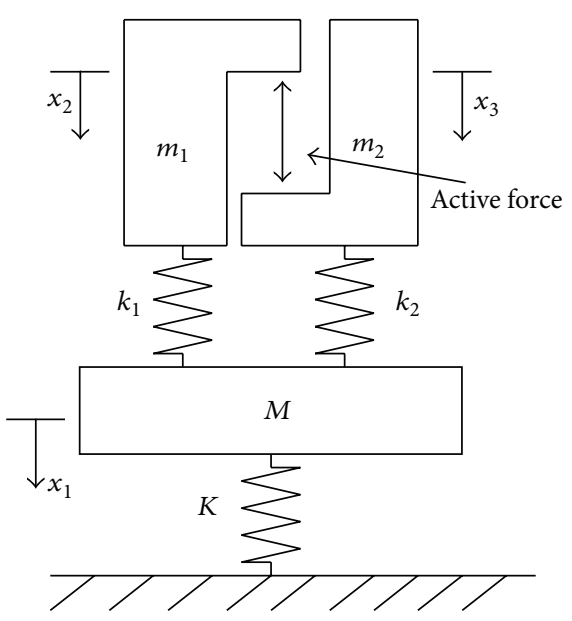

(c)

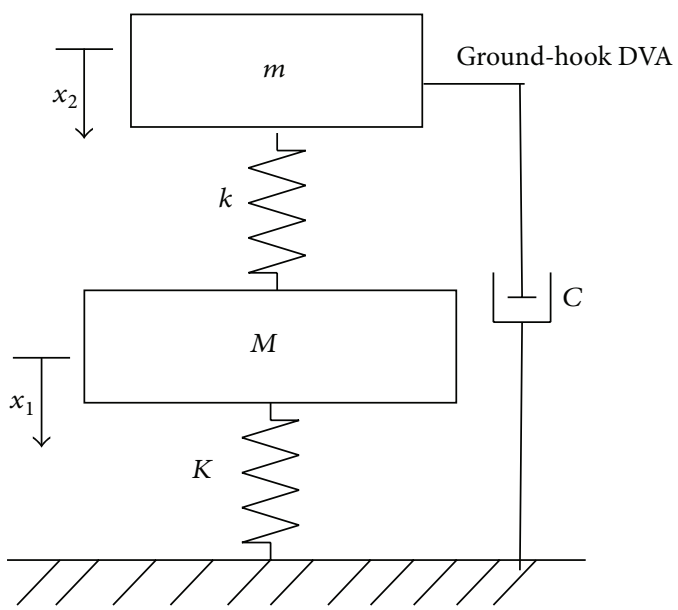

(b)

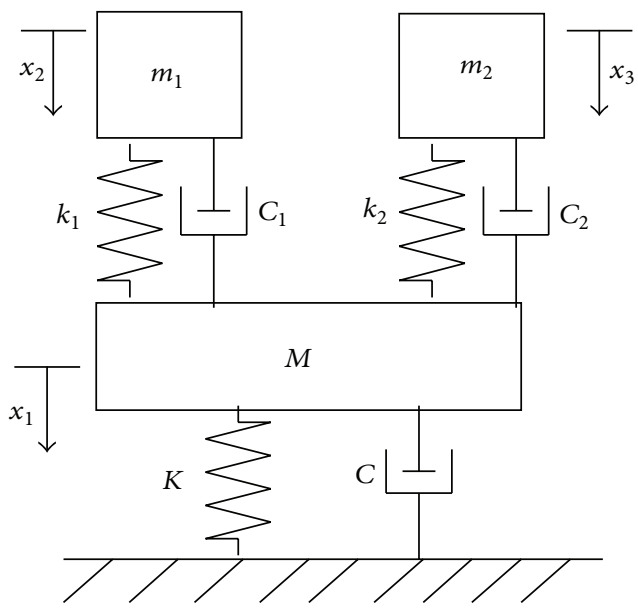

(d)

FIGURE 1: Four often-seen DVA's, (a) conventional, (b) ground-hook, (c) dual-mass, and (d) multimode.

As to multifrequency vibration suppression, Sun et al. [11] studied the differences in vibration absorption between the conventional DVA, the state-switched absorber (SSA), and dual-DVA (Figure 1(d)). Under the optimization process, their results showed that dual-DVA had very close performance as the SSA and both were, as expected, superior to the conventional DVA in multifrequency vibration suppression. The conclusion for dual-DVA design is as simple as tuning each DVA to a frequency wanted to be absorbed. Hill and Snyder [12] designed a dual mass absorber to suppress the vibration at multiple frequencies, which consisted of two rods (smooth and threaded) supporting two equal masses (bells) on both sides. This device was able to tune the first six natural frequencies, mixed in bending and torsion modes. The natural frequencies were yet restricted to be tuned in pairs, that is, first and second together, and so on. In 2006, Wang and Cheng [13] used the impedance technique to design a multifrequency absorber by varying single beam's several cross-sectional areas such that the beam's natural frequencies coincided with the designated frequencies. Although a geometrically nonuniform beam could theoretically attain any desired multifrequency, it however required very tedious calculations and complicated shaping in manufacturing.

In real world, most of the mechanical systems are subjected to periodic rather than simple harmonic excitation. Mathematically, periodic excitation is composed of a series of infinite harmonics in integer multiples of base frequency. Nevertheless, only are the first few components significant in mechanical vibration. In general cases, the first three harmonics contain about $90 \%$ of the overall excitation. To suppress periodic excitation, one may employ the multifrequency DVA technique [11] and tune three DVA's frequencies to the first three harmonics. The consequence, yet, will be significant mass loading to the main system. The mass loading effect may be reduced by lowering the DVA's mass ratio but the cost would be the absorber highly sensitive to excitation frequency variation. The present investigation is hence motivated by the necessity of developing a simple, passive PVA of relatively low mass ratio for periodic excitation. The derived dualbeam PVA (Figure 2) in this paper will prove itself to meet 


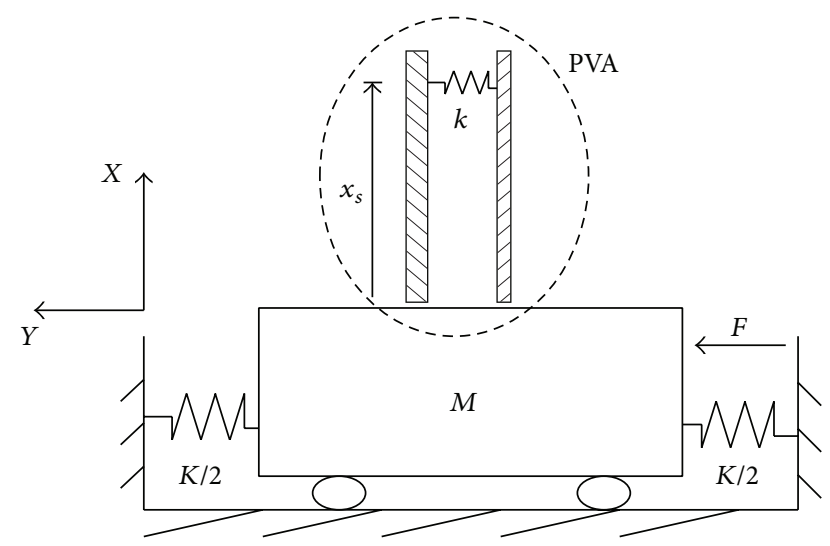

FIGURE 2: The schematic diagram of primary system mounted with a dual-beam PVA.
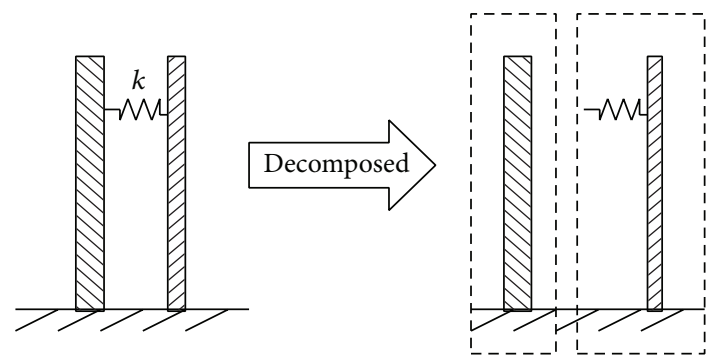

FIGURE 3: Decomposition of the dual-beam PVA.

the goal and to provide significant applicability for vibration engineers.

\section{Frequency Equation of PVA}

Figure 2 schematically shows the designed PVA mounted on a primary system to resist periodic excitation. $M$ and $K$ denote the primary system's mass and stiffness, respectively. The PVA is composed of two cantilever beams (dual-beam) with an intermediate spring of constant $k$. The intermediate spring is connected at the position of $x_{s}$. For simplicity, though not necessary, the two beams' length is assumed to be the same. $\rho_{i}, A_{i}, E_{i}$, and $I_{i}, i=1,2$, stand for the $i$ th beam's density, cross-sectional area, Young's modulus, and area moment of inertia, respectively.

Utilizing the structure combination technique and the receptance method $[14,15]$, this PVA can be divided into two parts, as shown in Figure 3, and the corresponding frequency equation is

$$
\alpha(\omega)+\beta(\omega)=0,
$$

where $\alpha(\omega)$ is the receptance of the first cantilever beam and can be expressed [15] as

$$
\alpha(\omega)=\sum_{n=1}^{M_{1}} \frac{\Phi_{n}^{2}\left(x_{s}\right)}{\rho_{1} A_{1}\left(\omega_{1 n}^{2}-\omega^{2}\right) \int_{0}^{L} \Phi_{n}^{2}(x) d x} .
$$

Similarly, $\beta(\omega)$ stands for the receptance of the second cantilever beam plus spring,

$$
\beta(\omega)=\sum_{n=1}^{M_{2}} \frac{\Phi_{n}^{2}\left(x_{s}\right)}{\rho_{2} A_{2}\left(\omega_{2 n}^{2}-\omega^{2}\right) \int_{0}^{L} \Phi_{n}^{2}(x) d x}+\frac{1}{k},
$$

where $\Phi_{n}(x)$ is a cantilever beam's $n$th mode shape. $\omega_{i n}$ is the $i$ th beam's $n$th natural frequency. $M_{1}$ and $M_{2}$, respectively, are the mode numbers of two beams. Note that the cantilever beam is assumed to be of Bernoulli-Euler's model and $\omega$ (or $\left.\omega_{p}, p=1,2, \ldots\right)$ denotes the PVA's natural frequency to be solved.

The design criterion is to make the PVA's first few natural frequencies be in integer multiples of the base frequency of periodic excitation; that is, $\omega_{p}=p \omega_{f}, p=1,2, \ldots$. Substituting (2) and (3) into (1), and it is obtained that

$$
\begin{aligned}
& \sum_{n=1}^{M_{1}} \frac{\Phi_{n}^{2}\left(x_{s}^{*}\right)}{\rho_{1} A_{1}\left(\omega_{1 n}^{2}-\left(p \omega_{f}\right)^{2}\right) \int_{0}^{L} \Phi_{n}^{2}(x) d x} \\
& +\sum_{n=1}^{M_{2}} \frac{\Phi_{n}^{2}\left(x_{s}^{*}\right)}{\rho_{2} A_{2}\left(\omega_{2 n}^{2}-\left(p \omega_{f}\right)^{2}\right) \int_{0}^{L} \Phi_{n}^{2}(x) d x}+\frac{1}{k}=0, \\
& p=1,2, \ldots,
\end{aligned}
$$

where $x_{s}^{*}=x_{s} / L$ is the normalized spring location and $p \omega_{f}$ is the PVA's $p$ th natural frequency.

For simplicity, a dimensionless parameter, $\alpha_{n}=\omega_{1 n} /$ $\omega_{11}=\omega_{2 n} / \omega_{21}$ denoting the known ratios of a cantilever beam's $n$th natural frequency to its first natural frequency, is introduced. Equation (4) is then rewritten as

$$
\begin{aligned}
& \sum_{n=1}^{M_{1}} \frac{\Phi_{n}^{2}\left(x_{s}^{*}\right)}{\rho_{1} A_{1}\left(\omega_{11}^{2} \alpha_{n}^{2}-\left(p \omega_{f}\right)^{2}\right) \int_{0}^{L} \Phi_{n}^{2}(x) d x} \\
& \quad+\sum_{n=1}^{M_{2}} \frac{\Phi_{n}^{2}\left(x_{s}^{*}\right)}{\rho_{2} A_{2}\left(\omega_{21}^{2} \alpha_{n}^{2}-\left(p \omega_{f}\right)^{2}\right) \int_{0}^{L} \Phi_{n}^{2}(x) d x}+\frac{1}{k}=0 .
\end{aligned}
$$

We further define two design variables, $\omega_{1}=\omega_{11} / \omega_{f}$ and $\omega_{2}=\omega_{21} / \omega_{f}$, denoting the ratios of the first and the second cantilever beam's fundamental natural frequency to the base frequency of excitation. Equation (5) becomes

$$
\begin{aligned}
\sum_{n=1}^{M_{1}} & \frac{\Phi_{n}^{2}\left(x_{s}^{*}\right)}{\left(\omega_{1}^{2} \alpha_{n}^{2}-p^{2}\right) \int_{0}^{L} \Phi_{n}^{2}(x) d x} \\
& +\sum_{n=1}^{M_{2}} \frac{\Phi_{n}^{2}\left(x_{s}^{*}\right)}{\left(\omega_{2}^{2} \alpha_{n}^{2}-p^{2}\right) \int_{0}^{L} \Phi_{n}^{2}(x) d x} \frac{\rho_{1} A_{1}}{\rho_{2} A_{2}}+\frac{\rho_{1} A_{1} \omega_{f}^{2}}{k}=0 .
\end{aligned}
$$




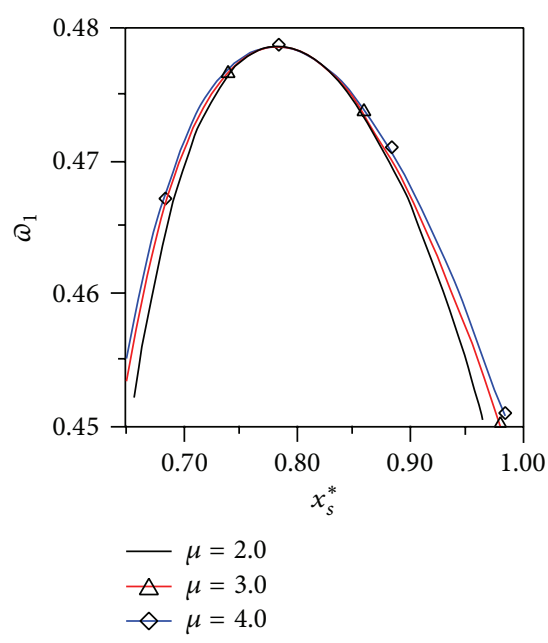

(a)

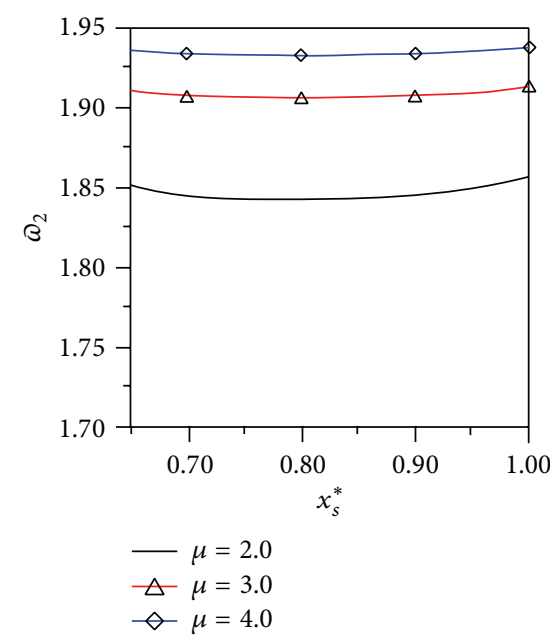

(b)

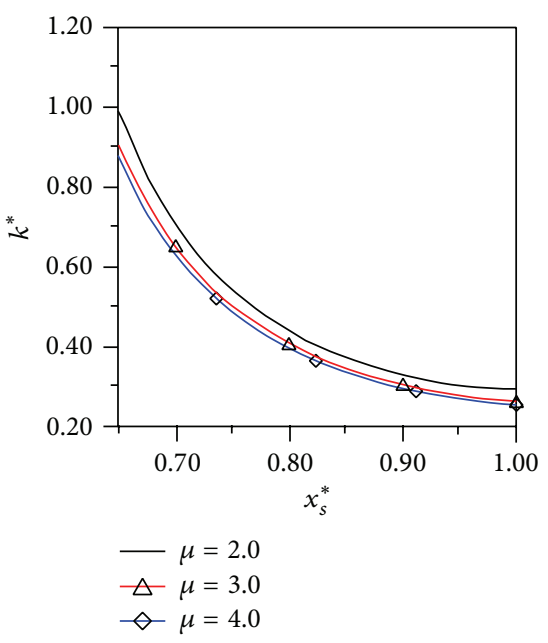

(c)

FIGURE 4: Variations of design parameters to different $x_{s}^{*}$.

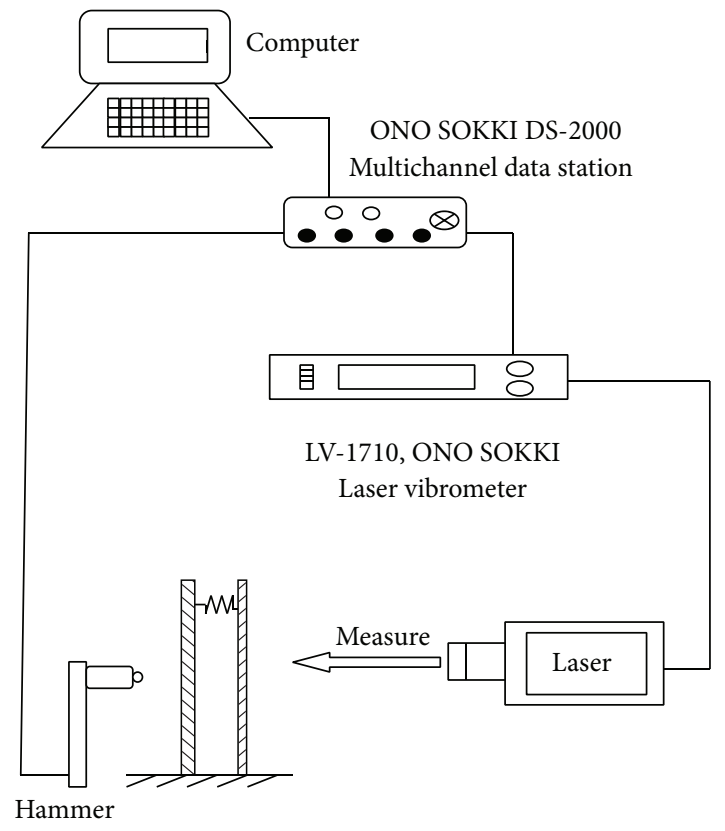

FIGURE 5: The schematic diagram of PVA experimental test.

Utilizing the orthogonal property of beam's mode shapes and one normalized equation, $\int_{0}^{L} \Phi_{n}^{2}(x) d x=L,(6)$ is simplified to be

$$
\sum_{n=1}^{M_{1}} \frac{\Phi_{n}^{2}\left(x_{s}^{*}\right)}{\left(\omega_{1}^{2} \alpha_{n}^{2}-p^{2}\right)}+\sum_{n=1}^{M_{2}} \frac{\Phi_{n}^{2}\left(x_{s}^{*}\right)}{\left(\omega_{2}^{2} \alpha_{n}^{2}-p^{2}\right)} \frac{\rho_{1} A_{1}}{\rho_{2} A_{2}}+\frac{L \rho_{1} A_{1} \omega_{f}^{2}}{k}=0 .
$$

Subsequently, further reduction yields

$$
\sum_{n=1}^{M_{1}} \frac{\Phi_{n}^{2}\left(x_{s}^{*}\right)}{\left(\omega_{1}^{2} \alpha_{n}^{2}-p^{2}\right)}+\sum_{n=1}^{M_{2}} \frac{\Phi_{n}^{2}\left(x_{s}^{*}\right)}{\left(\omega_{2}^{2} \alpha_{n}^{2}-p^{2}\right) \mu}+\frac{1}{k^{*}}=0
$$

where $\mu=\left(\rho_{2} A_{2}\right) /\left(\rho_{1} A_{1}\right)$ denotes another design variable, the mass ratio of the two beams. The normalized spring constant $k^{*}=k\left(\omega_{1}^{2} L^{3}\right) /\left(\beta_{1}^{4} E_{1} I_{1}\right)$ is the last design variable, where $\beta_{1}$ is the first mode wave number of single cantilever beams; that is, $\Phi_{1}=\left(\sinh \beta_{1} x-\sin \beta_{1} x\right)-\lambda_{1}\left(\cosh \beta_{1} x-\right.$ $\left.\cos \beta_{1} x\right)$. Equation (8) presents the PVA's frequency equation in a dimensionless form. Mathematically, we have derived the design problem as an explicit function of five design variables $\left(\omega_{1}, \omega_{2}, k^{*}, x_{s}^{*}\right.$, and $\left.\mu\right)$; that is, $f\left(\omega_{1}, \omega_{2}, k^{*}, x_{s}^{*}, \mu\right)=0$. It implies that the maximum number of PVA's frequencies could be tuned up to five; that is, PVA's first five natural frequencies might be determined via appropriate selection of the five design variables. It is yet unnecessary and nonrealistic to tune so many frequencies since the first three harmonics usually contain more than $90 \%$ of the excitation. To tune higher harmonics more closely it will sacrifice the accuracy of lower ones, which are yet the most important. In the following examples, we will tune the PVA only up to the first three natural frequencies; that is, $p=1 \sim 3$.

\section{Simulations and Experimental Verification}

From (8), it is seen that there is room to set two out of five design variables as known values. Prior to doing that, it is helpful to realize the intercorrelation between all design variables. We first set the mass ratio $(\mu)$, once at a time, at a specific value and look into the correlations between $x_{s}^{*}$ and the other three parameters $\left(\omega_{1}, \omega_{2}\right.$, and $\left.k^{*}\right)$. The curves are drawn in Figure 4 . It is seen that all parameters vary with $x_{s}^{*}$ in a nonlinear trend. From the shown curves, it is obvious that $\omega_{1}$ and $k^{*}$ are more sensitive to $x_{s}^{*} . \omega_{2}$ curves are rather flat relative to $x_{s}^{*}$ variations. $\omega_{2}$, yet, shows much larger sensitivity (curves farther apart) to $\mu$ 's change than $\omega_{1}$ and $k^{*}$ do. These correlations shown in Figure 4 provide us with a reference to determine the design variables, although not in an optimal sense. For example, one may first select appropriate $\mu$ and $\omega_{2}$ (most sensitive); then, from its corresponding $x_{s}^{*}$ one 


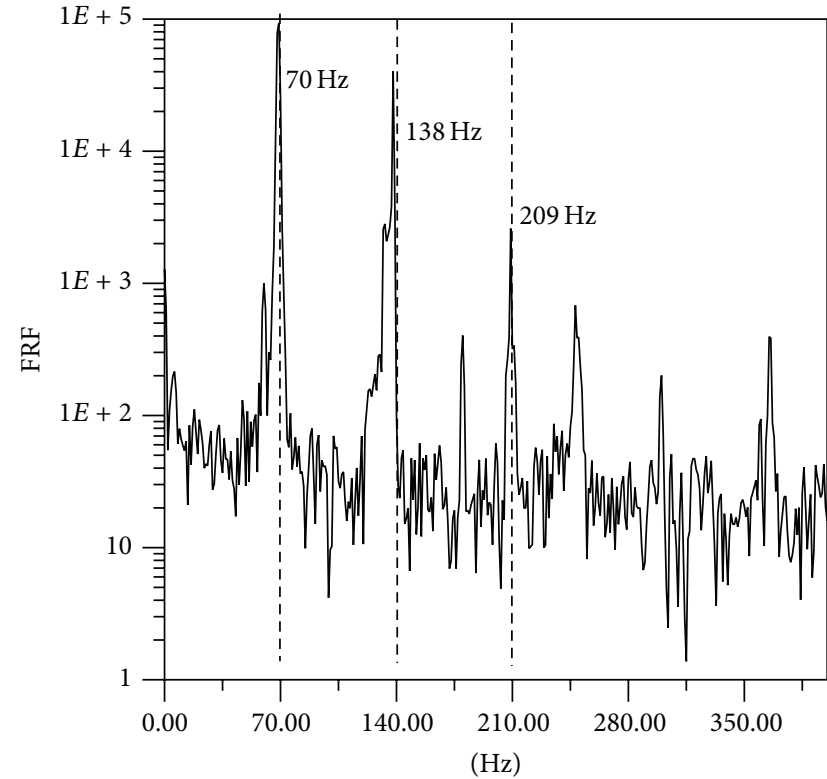

(a)

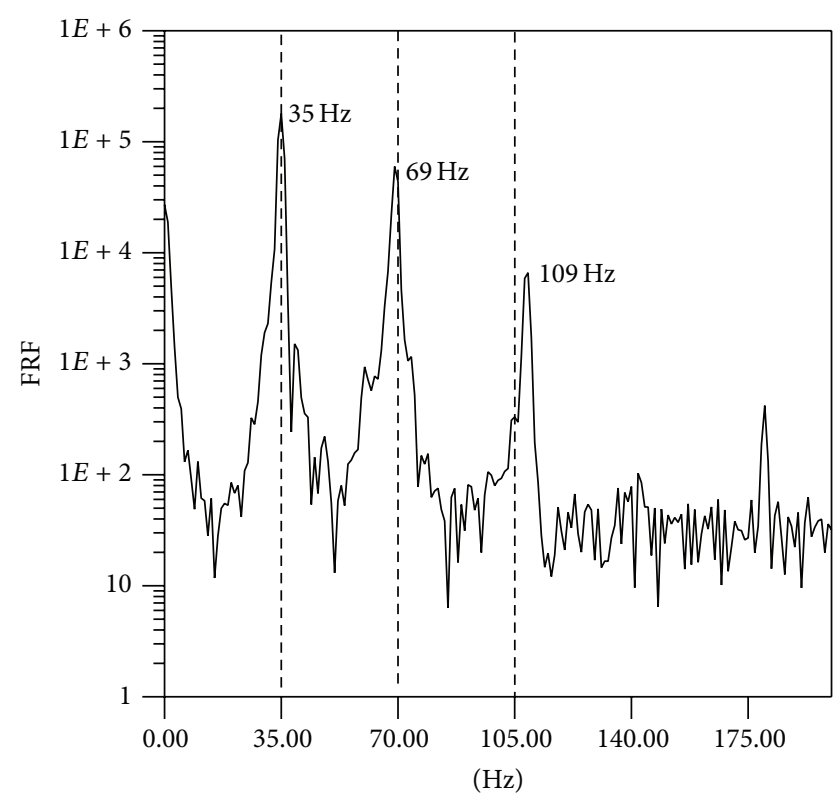

(b)

FIgURE 6: Experimental FRF of (a) specimen A and (b) specimen B.

TABLE 1: The geometrical and material properties of PVA.

(a)

\begin{tabular}{lcc}
\hline & $\begin{array}{c}\text { Specimen A } \\
\text { First beam (SUS304) }\end{array}$ & Second beam $(\mathrm{Al})$ \\
\hline Density $\left(\mathrm{kg} / \mathrm{m}^{3}\right)$ & $\rho_{1}=7800$ & $\rho_{2}=2710$ \\
Modulus $\left(\times 10^{9} \mathrm{~N} / \mathrm{m}^{2}\right)$ & $E_{1}=200$ & $E_{2}=69$ \\
Thickness $(\mathrm{mm})$ & $h_{1}=0.88$ & $h_{2}=3.68$ \\
Width $(\mathrm{mm})$ & $b_{1}=20.0$ & $b_{2}=27.57$ \\
Length $(\mathrm{mm})$ & $L_{1}=175.0$ & $L_{2}=175.0$ \\
\hline
\end{tabular}

Spring constant: $k=0.791 \mathrm{KN} / \mathrm{m}$; connecting location: $x_{s}=171.5 \mathrm{~mm}$. $f_{1}=70 \mathrm{~Hz}$.

(b)

\begin{tabular}{lcc}
\hline & $\begin{array}{c}\text { Specimen B } \\
\text { First beam (SUS304) }\end{array}$ & Second beam $(\mathrm{Al})$ \\
\hline Density $\left(\mathrm{kg} / \mathrm{m}^{3}\right)$ & $\rho_{1}=7800$ & $\rho_{2}=2710$ \\
Modulus $\left(\times 10^{9} \mathrm{~N} / \mathrm{m}^{2}\right)$ & $E_{1}=200$ & $E_{2}=69$ \\
Thickness $(\mathrm{mm})$ & $h_{1}=1.19$ & $h_{2}=4.97$ \\
Width $(\mathrm{mm})$ & $b_{1}=25.0$ & $b_{2}=34.47$ \\
Length $(\mathrm{mm})$ & $L_{1}=250.0$ & $L_{2}=250.0$ \\
\hline
\end{tabular}

Spring constant: $k=0.8301 \mathrm{KN} / \mathrm{m}$; Connecting location: $x_{s}=245.0 \mathrm{~mm}$. $f_{1}=35 \mathrm{~Hz}$.

can continue for suitable $\omega_{1}$ and $k^{*}$. The above-mentioned process is just one of many possibilities. Two examples solved by the above process are illustrated and the calculations are given in Table 1.

A simple experiment is then set up to verify if the obtained PVA (Table 1) has integer multiples of the base frequency as we desired. Figure 5 shows the setup of experimental apparatus. The displacement and corresponding FRFs of the
TABLE 2: Simulated response amplitudes due to periodic excitation of $f=120 \mathrm{~Hz}$.

\begin{tabular}{lccc}
\hline Wave & Without absorber & With DVA & With PVA \\
\hline Square wave & \multirow{2}{*}{0.33} & 0.012 & 0.004 \\
& & $(-28.8 \mathrm{~dB})$ & $(-38.3 \mathrm{~dB})$ \\
Saw-tooth & 0.18 & 0.026 & 0.007 \\
& & $(-16.8 \mathrm{~dB})$ & $(-28.2 \mathrm{~dB})$ \\
\hline
\end{tabular}

TABLE 3: Simulated and experimental results with a saw-tooth wave of $f=55 \mathrm{~Hz}$.

\begin{tabular}{lcc}
\hline $\begin{array}{l}\text { Without absorber } \\
\text { experiment }\end{array}$ & $\begin{array}{c}\text { With PVA } \\
\text { simulation }\end{array}$ & $\begin{array}{c}\text { With PVA } \\
\text { experiment }\end{array}$ \\
\hline 0.014 & $\begin{array}{c}0.001 \\
(-22.9 \mathrm{~dB})\end{array}$ & $\begin{array}{c}0.0015 \\
(-19.4 \mathrm{~dB})\end{array}$ \\
\hline
\end{tabular}

PVA are picked up and transferred by an ONO SOKKI Laser Vibrometer (LV-1710). Figure 6 shows the FRFs of two specimens and it is seen that the first three natural frequencies are very close to integer multiples of the base frequency, one $70 \mathrm{~Hz}$ and one $35 \mathrm{~Hz}$. The PVAs' first resonance frequencies coincided precisely with the base frequency but the second and the third showed some errors (3.80\% at most). The first three modes of specimen A are sketched in Figure 7 and it is seen that the first beam deforms more significantly than the second one for its larger flexibility (Table 1).

Now, implement the PVA onto the main system and analytically calculate the vibration reduction of the main system due to periodic excitation. The data of the main system are chosen as follows: $M=0.5 \mathrm{Kg}, K=6.125 \mathrm{kN} / \mathrm{m}$, and $f_{n}=17.6 \mathrm{~Hz}$. Unit square wave loading is first discussed. Note 


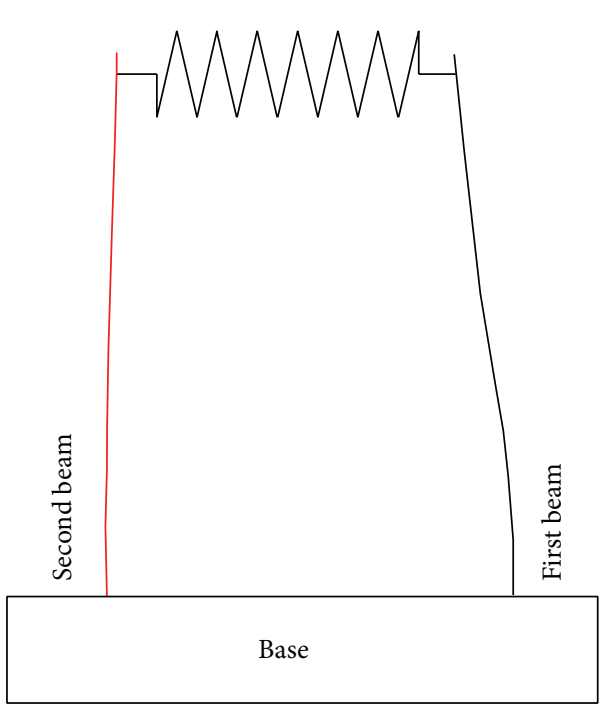

[Number 1]

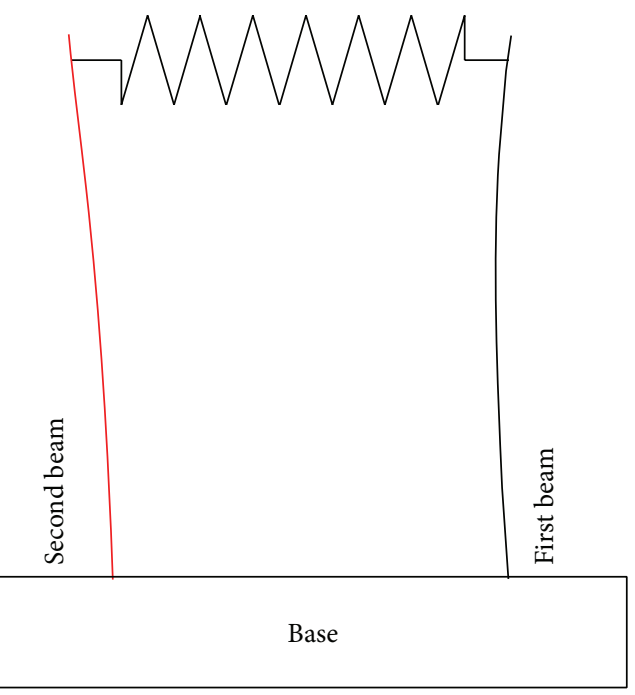

[Number 2]

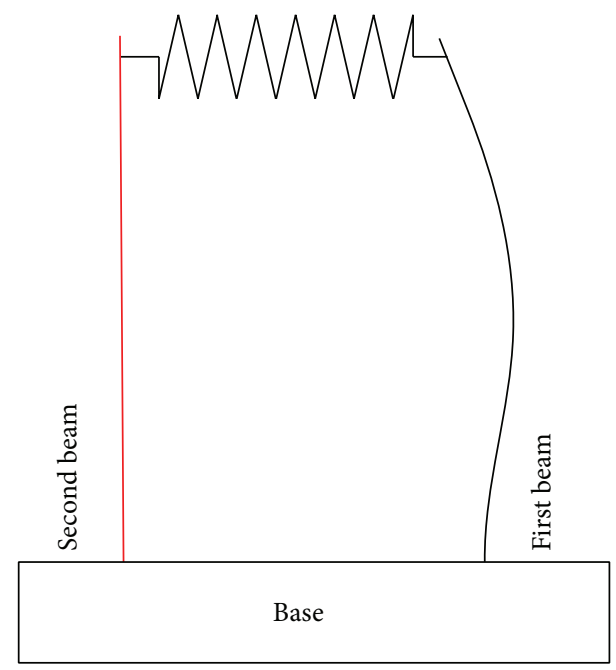

[Number 3]

FIgURE 7: The calculated first three modes of PVA.

that in the following simulations, the excitation frequency is set at $120 \mathrm{~Hz}$ throughout the paper unless compared to experiments, in which the excitation is set at $55 \mathrm{~Hz}$. Figure 8 shows three simulated response amplitudes of the primary system for (i) with no absorber, (ii) with a single DVA tuned at $\omega_{\mathrm{DVA}}=\omega_{f}$, and (iii) with the designed PVA. To have a fair comparison, DVA's mass is equal to PVA's. Figure 8(a) compares the responses of (i) and (iii) and the absorption effects of PVA are very significant. The reason we did not superimpose (ii) in Figure 8(a) is because under the same scale it is difficult to see the differences between (ii) and (iii). Instead, Figure 8(b) enlarges the responses of (ii) and (iii) and the differences between them reflect the contribution of higher harmonics. Note that the response amplitudes shown in the above figures, afterwards as well, are all in a dimensionless form by normalizing them with respect to the static displacement; that is, $X / X_{s}, X_{s}=$ $F / K$. Simulations for unit saw-tooth wave loading at the same frequency are illustrated in Figure 9 and similar results are obtained. From Figures 8(b) and 9(b), one may notice that the higher harmonics of saw-tooth and square-wave have different frequencies even though they are of the same base frequency. This can be explained after Fourier series expansion of the square-wave and saw-tooth functions,

$$
\begin{aligned}
& f(t)=\sum_{n=1}^{\infty} B_{n} \sin \left(n \omega_{f} t\right), \\
& B_{n}= \begin{cases}\frac{2}{n \pi}(1-\cos n \pi), & \text { for square wave, } \\
\frac{2}{n \pi}\left(1-\cos \frac{n \pi}{2}\right), & \text { for saw-tooth wave. }\end{cases}
\end{aligned}
$$

Since we used odd functions in both cases, the second harmonic $(n=2)$ of the square wave is zero by itself but not in the saw-tooth case and the third harmonics for both cases are of the same magnitude. That explains why Figure $8(\mathrm{~b})$ showed the 3rd harmonic and Figure 9(b) showed the 2nd 


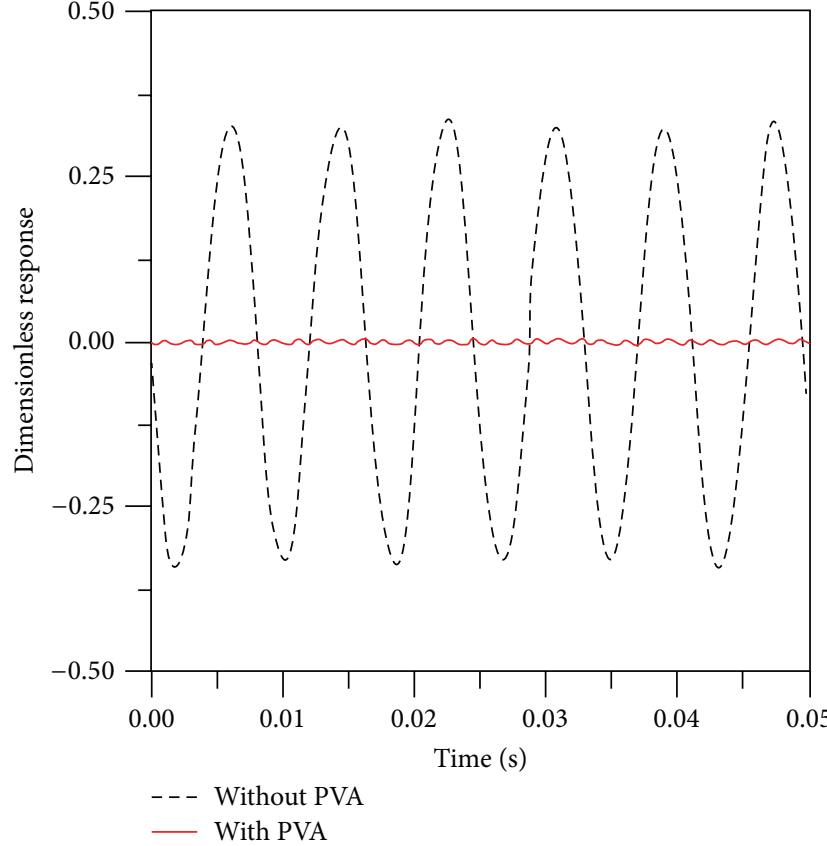

(a)

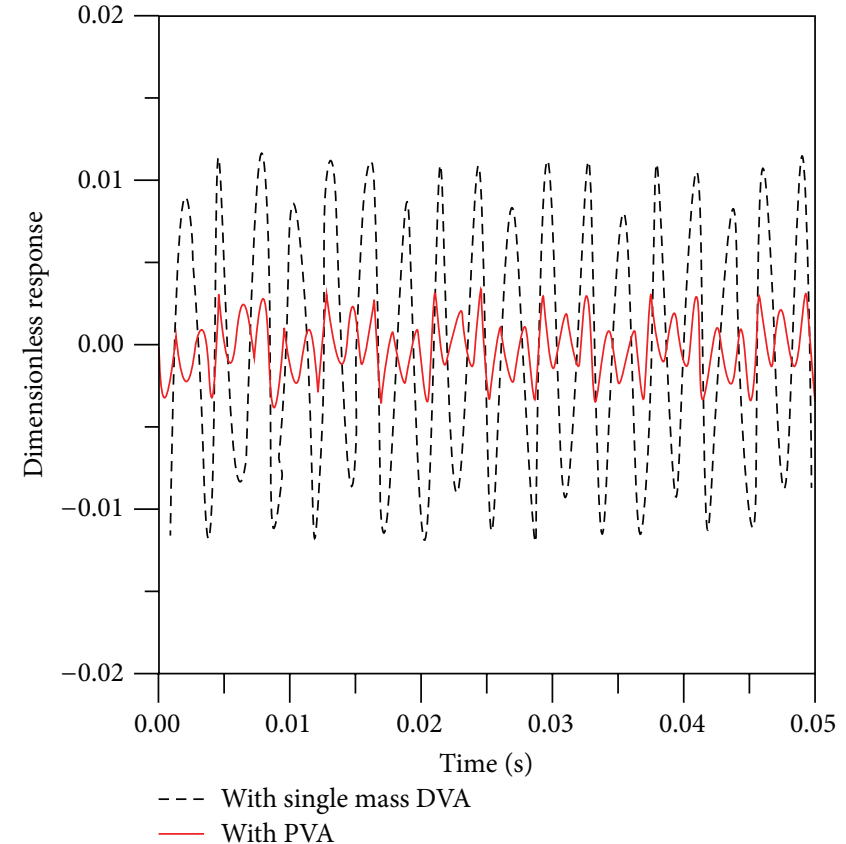

(b)

FIGURE 8: Simulation of PVA effect due to square wave loading for (a) overall absorption and (b) higher harmonics absorption.

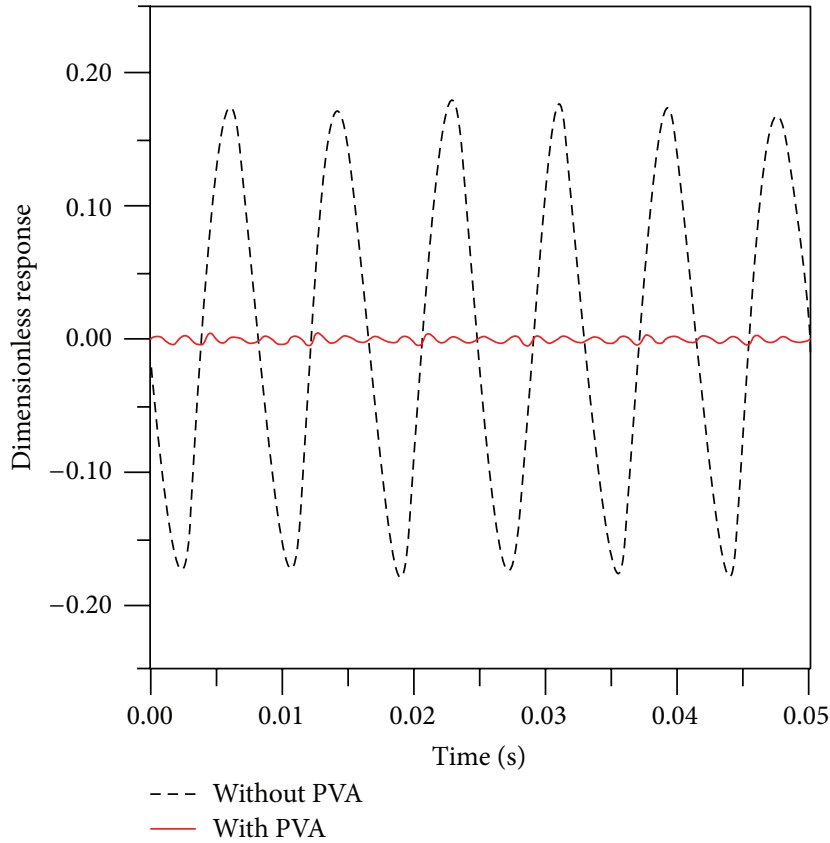

(a)

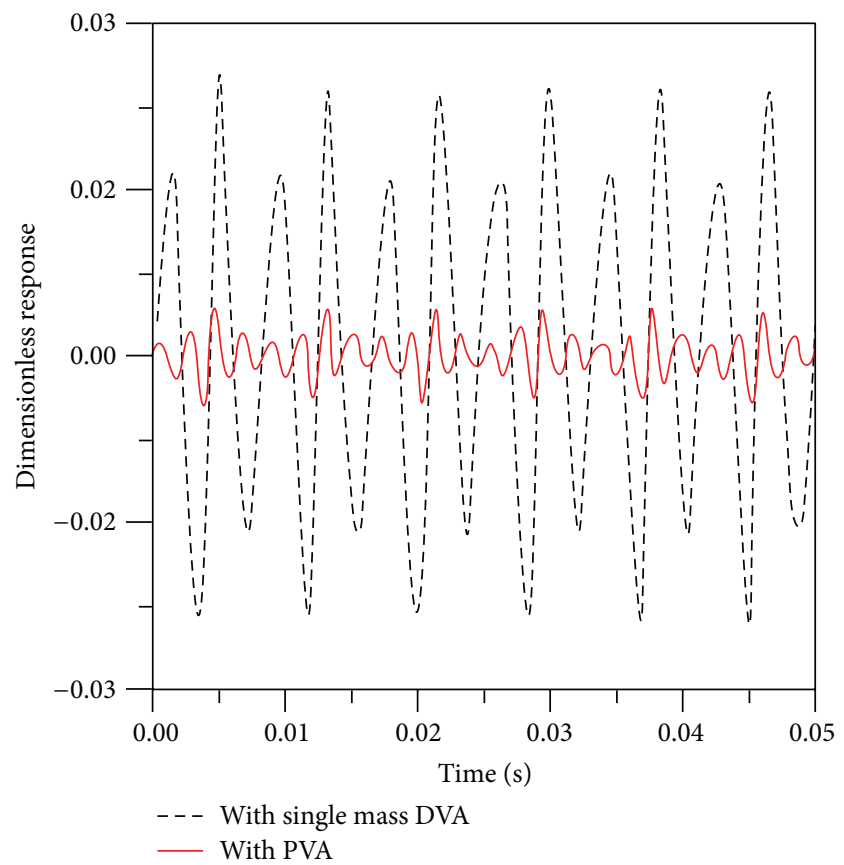

(b)

FIgURE 9: Simulation of PVA effect due to saw-tooth wave loading for (a) overall absorption and (b) higher harmonics absorption.

in the curves of (ii). Table 2 compares the absorption effects of all the simulated cases. In a square-wave case, a DVA is good enough to reduce the system response amplitude by $28.8 \mathrm{~dB}$ but just $16.8 \mathrm{~dB}$ in the case of saw-tooth because the square-wave originally contains no second harmonic. The
PVA yet reduces the system responses by $38.3 \mathrm{~dB}$ and $28.2 \mathrm{~dB}$, respectively, for the square-wave and the saw-tooth, contrast to the DVA, $9.5 \mathrm{~dB}$, and $11.4 \mathrm{~dB}$ more.

Experiments follow to verify the above simulations. Figure 10(a) shows the photo and Figure 10(b) shows the 


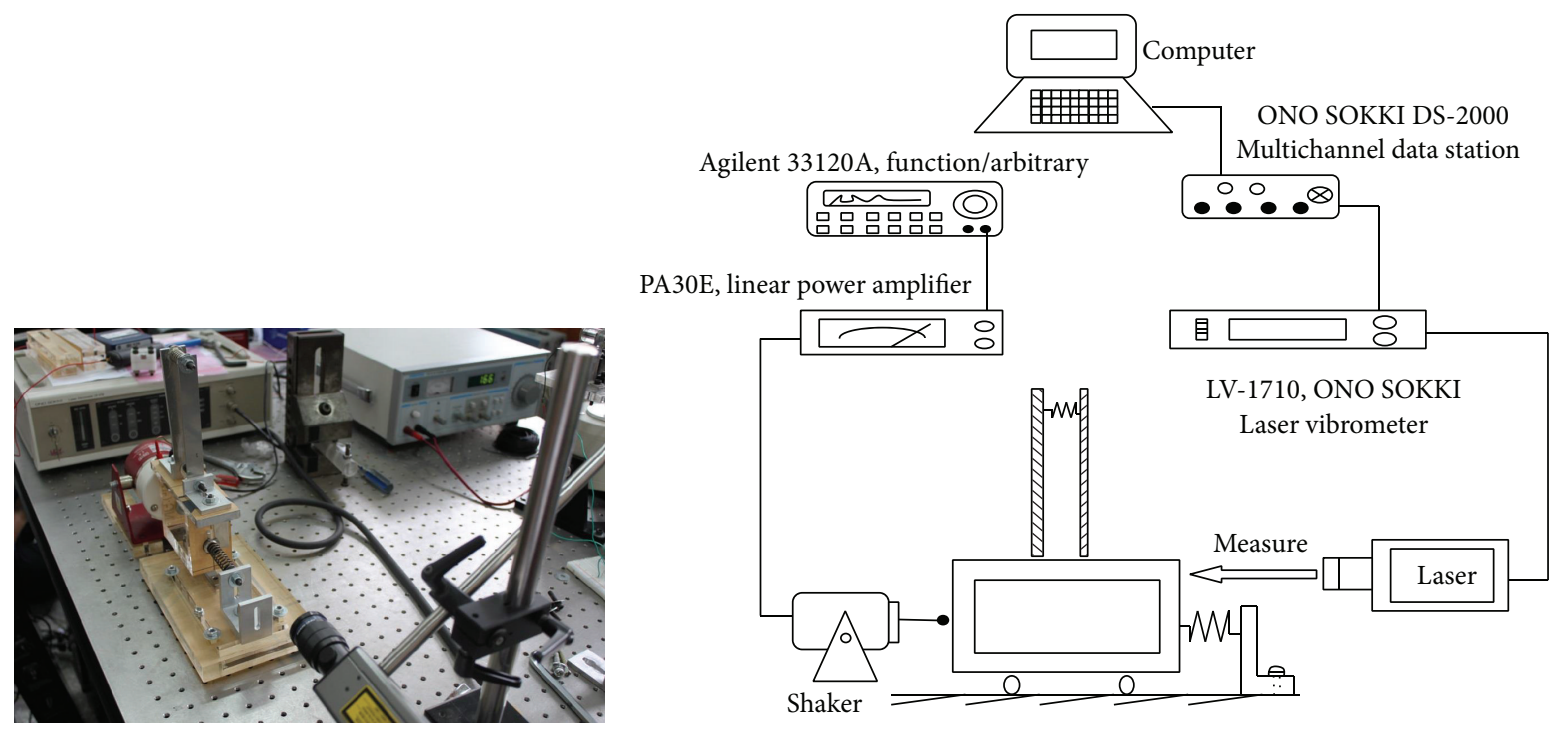

(a)

(b)

FIGURE 10: (a) Photo of experimental setup of main system with PVA and (b) schematic diagram.

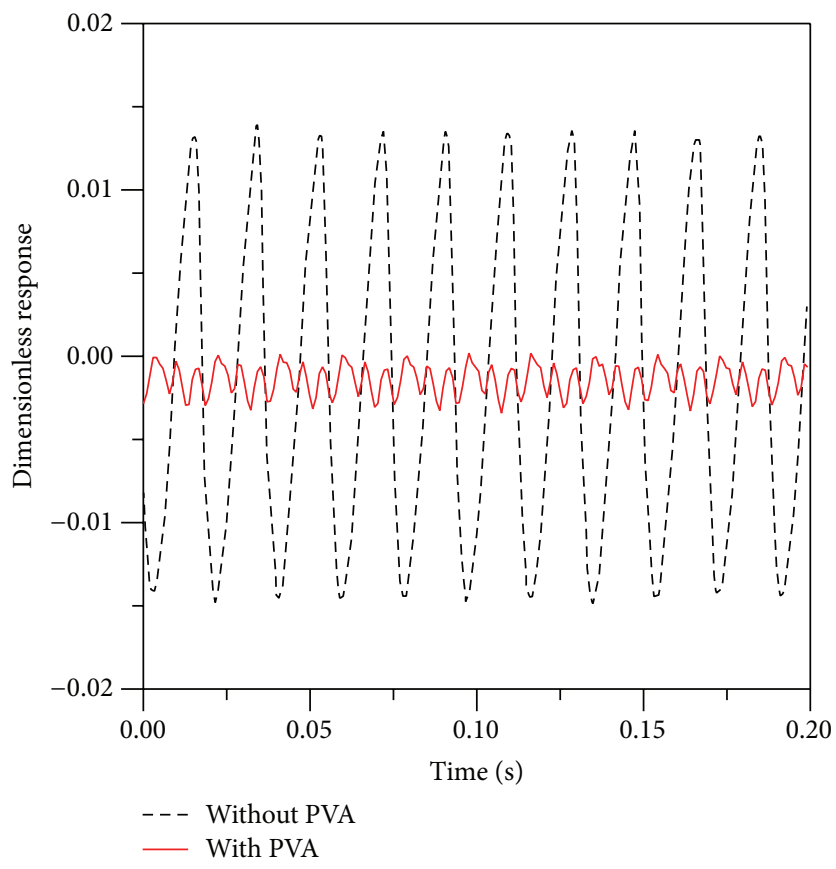

FIgURE 11: Experimental data of time response.

schematic diagram of apparatus setup. Figure 11 is the experimental time responses of the system with and without PVA under saw-tooth excitation of frequency $55 \mathrm{~Hz}$. It is observed that the main system's vibration is drastically reduced by PVA. Figure 12 compares the experimental data of Figure 11 and the simulation results. Note that at the first glance there seems a huge discrepancy between experiment and simulation but thorough inspection will reveal that the major difference comes from the nonzero DC term in the experimental data.

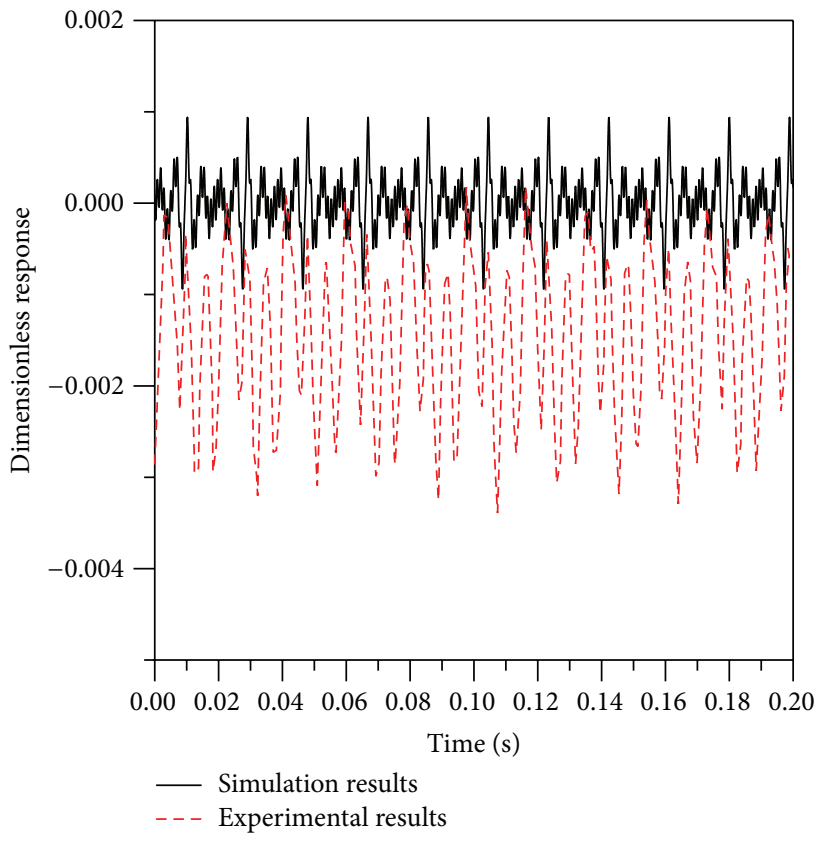

FIgURE 12: Comparison of the simulation and experimental data.

If one shifts the DC bias, the maximum amplitudes of the simulation and the experiment are, respectively, 0.001 and 0.0015 . Table 3 illustrates the data and the difference is about $3.5 \mathrm{~dB}$. This difference seems not to be negligible but in contrast to the overall effect of $19.4 \mathrm{~dB}$, this discrepancy is acceptable. This discrepancy can be attributed to the following causes. First, the PVA did not perfectly match the higher harmonics (3.8\% error) and secondly all the analyses were based on undamped situation. Though no intended damper was added in the primary system or PVA, there 


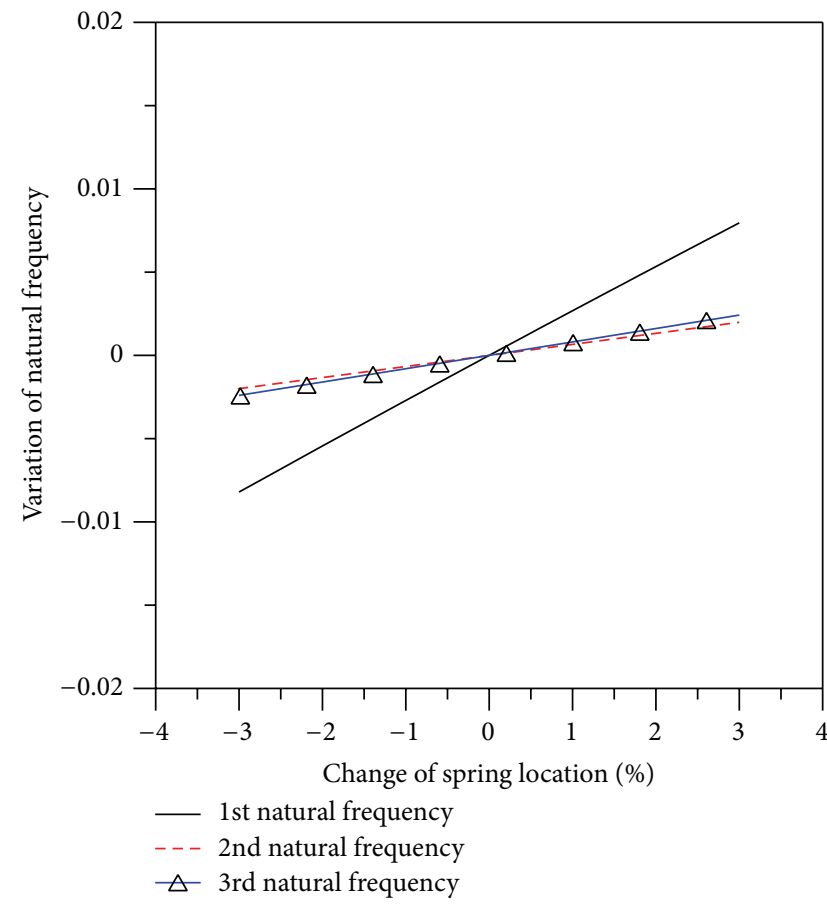

(a)

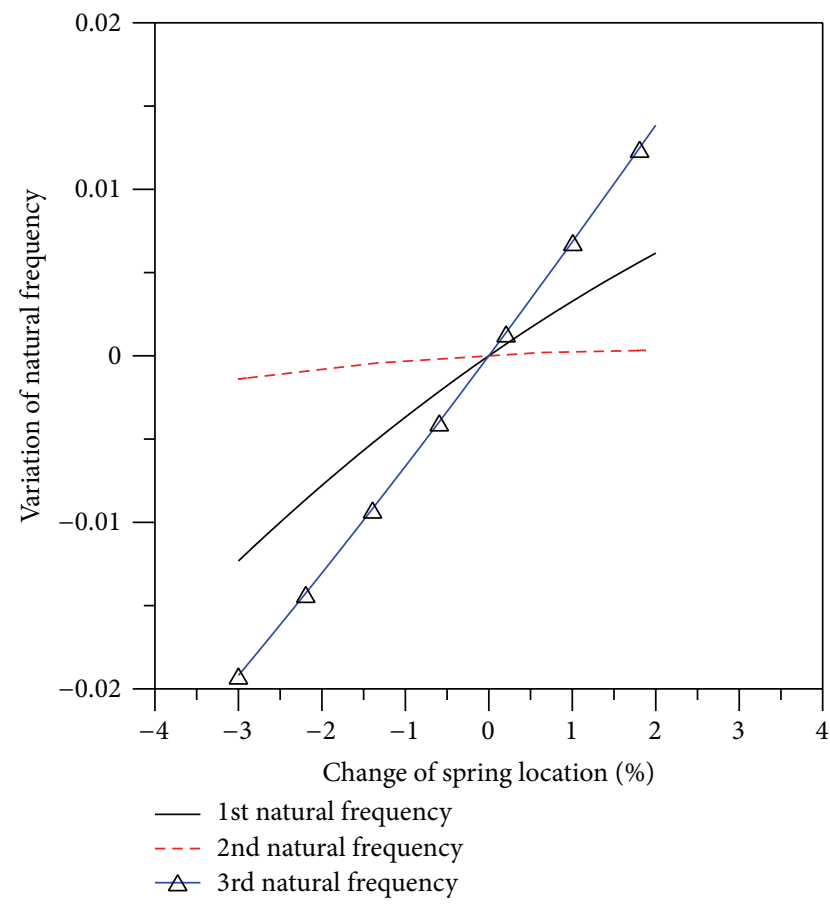

(b)

FIGURE 13: PVA's natural frequencies vary with (a) spring's stiffness $k^{*}$ and (b) spring's location $x_{s}^{*}$.

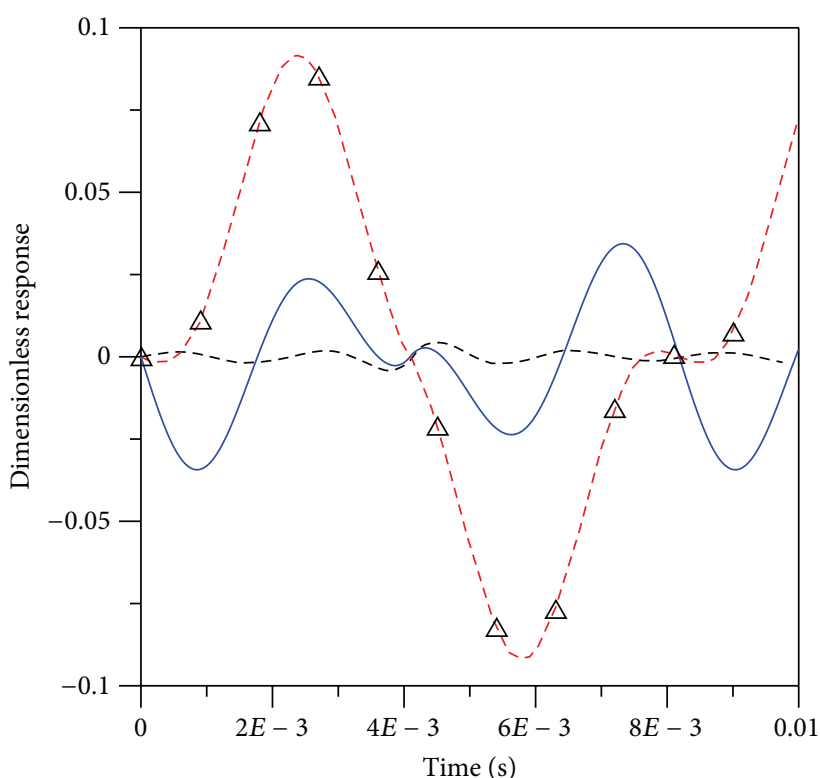

- - $0 \%$ mismatch

- $1 \%$ mismatch (adjusts $\left.k^{*}\right)$

$-A-1 \%$ mismatch (no adjustment)

(a)

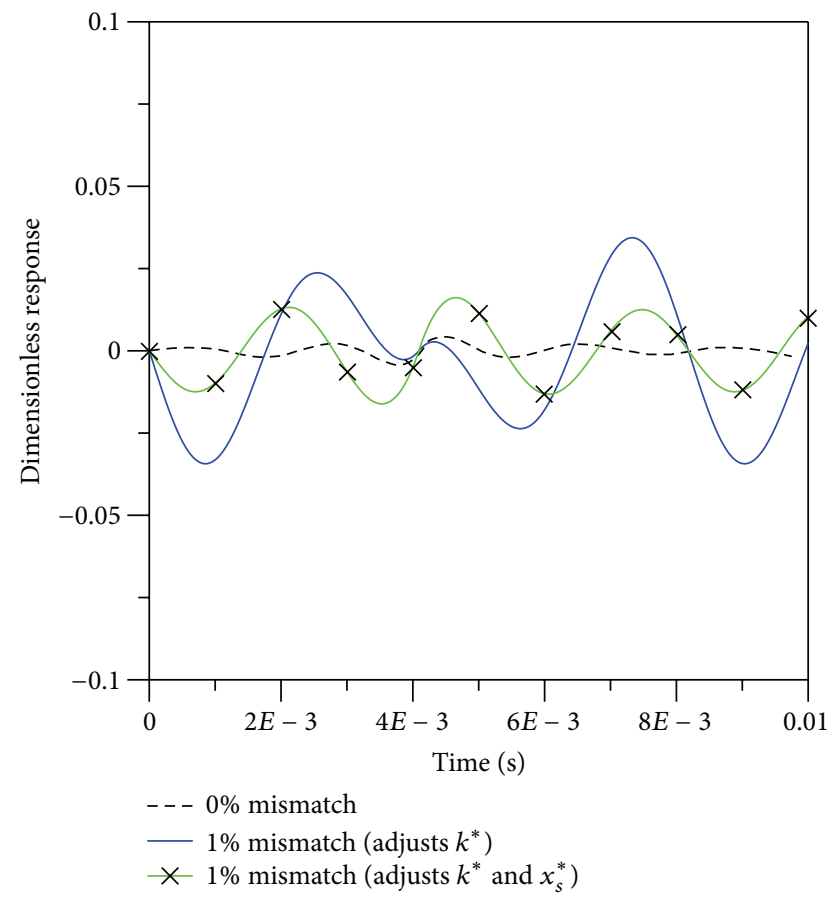

(b)

FIGURE 14: System response to small mismatch frequency with (a) one variable and (b) two-variable adjustment. 


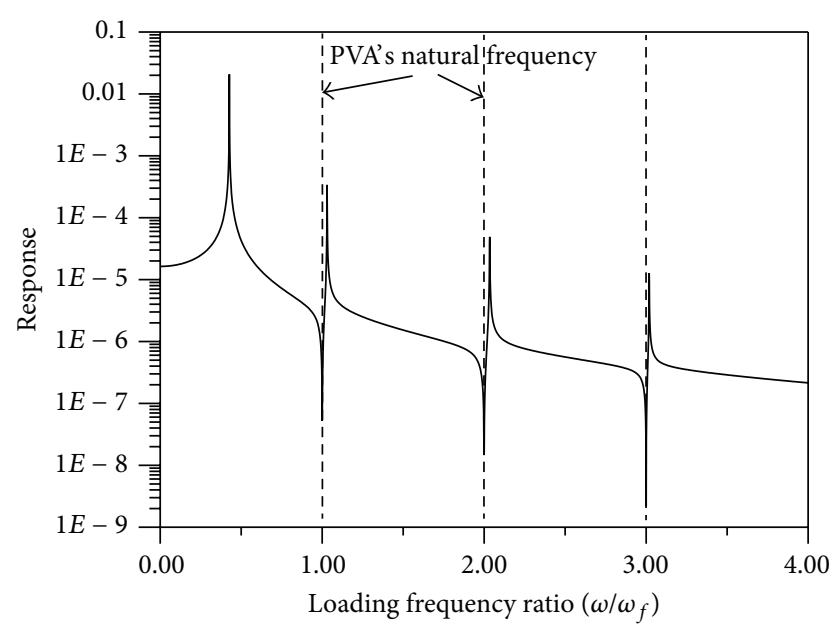

FIGURE 15: FRF of the combined structure.

exists damping in the real world. A small amount of damping would shift the best absorption frequency and reduces the attenuation effects.

Though the simulation has shown PVA's excellent vibration absorbability, to meet engineering applications, the PVA has to be adjustable to slight excitation frequency variation without reconstructing PVA. Reviewing all of the design variables, $k^{*}$ and $x_{s}^{*}$, the spring's stiffness and position appear to be the two easiest ones for adjustment without reassembling the structure. Figure 13 illustrates how the PVA's first three resonance frequencies vary with (a) the spring stiffness and (b) the spring location. The ordinates are the dimensionless frequency variations; that is, $\Delta \omega_{i} / \omega_{i}, i=$ $1,2,3$. As anticipated, both the spring stiffness and location change PVA's resonance frequencies monotonically, that is, changing $k^{*}$ and $x_{s}^{*}$, will shift all the first three frequencies in the same direction but of different sensitivity. For instance, the first frequency $(p=1)$ is the most sensitive to $k^{*}$ but the third one $(p=3)$ is the most sensitive to $x_{s}^{*}$. Since all the sensitivities are not in proportion, it is unable to tune $k^{*}, x_{s}^{*}$ and simultaneously retain the first three natural frequencies in exact integer multiples as wanted. The objective is to reduce the response to a maximum amount; therefore, the first harmonic should be adjusted to the least error. Figure 14 shows some of the solutions to reducing the mismatch effect. Figure 14(a) compares the system responses of perfect match, $1 \%$ frequency mismatch without any adjustment and with single $k^{*}$ adjustment. It is seen that the system's vibration level increased by mismatch and was obviously attenuated by simply tuning the spring stiffness constant (3.78\% increase). Figure 14(b) compares the differences of tuning one and two variables. With simultaneous adjustment of $k^{*}$ and $x_{s}^{*}$, the response amplitude is further reduced. From the above illustration we are confident that the designed PVA offers satisfactory periodic vibration absorbability and can be tuned to correspond to slightly external frequency variations.

Our calculations revealed, not shown in this paper, that the adjustment yielded poor results for the 3rd harmonic as the mismatch exceeded 3\%. It is yet still assured that the first frequency can always be adjusted to meet the base frequency $\omega_{f}$ even for larger excitation frequency variation and the PVA still performs better than a single DVA. This can be verified by comparing the response amplitudes. From Table 2, the amplitude with a DVA is 0.026 and the maximum amplitude in Figure $14(\mathrm{~b})$ is around 0.02, less than DVA's. Figure 15 shows the FRF of the combined primary-PVA system. The dash lines denote the PVA's resonance frequencies and they become antiresonance frequencies of the combined system.

\section{Conclusions}

In this paper, a periodic vibration absorber (PVA) of dualbeam type is for the first time ever designed, analytically discussed, and experimentally verified. The PVA consists of two cantilever beams interconnected with an intermediate discrete spring. When the spring is appropriately chosen and located, the PVA can very effectively attenuate any periodic excitation. The frequency equation of the designed PVA was theoretically derived from the receptance method and subsequently arranged in a general, dimensionless form in terms of five design variables. Enforcing the PVA's resonance frequencies in integer multiples and solving the frequency equation, the PVA's parameters were determined according to the excitation base frequency. This paper demonstrated examples of setting the PVA's first three resonance frequencies in integer multiples of the base frequency and the results appeared to be accurate by experimental verification.

The responses of the primary system with/without the designed PVA were calculated in simulations. As expected, the results showed PVA's excellent absorption effect to periodic excitation. Experiments followed to verify the theoretical calculations and satisfactory agreement has been obtained. From the shown examples, PVA could improve the response amplitude 9.5 11.4 dB more, compared to a single DVA. The error of PVA's absorption between simulation and experiment was about $3.5 \mathrm{~dB}$ that might be attributed to the design variables' variations and the ignored damping existed in structures. The ability of adjusting spring's stiffness and location to compensate the mismatch of excitation frequency was studied as well. The results showed that PVA could be well tuned if mismatch was less than $3 \%$ and the tuned PVA still performed better than a single DVA. The derived PVA in this paper is useful for the audience in vibration engineering and is believed to provide an efficient and effective tool for suppressing periodic vibration of structures.

\section{Nomenclature}

$A_{i}$ : Cross-sectional area of $i$ th beam

$E_{i}$ : Young's modulus of $i$ th beam

$I_{i}$ : Area moment of inertia of $i$ th beam

$k$ : Stiffness of an intermediate spring

$k^{*}$ : Normalized spring constant

$K$ : Stiffness of the primary system

$L$ : Length of beam

$M$ : Mass of the primary system

$x_{s}$ : Spring location

$x_{s}^{*}$ : Normalized spring location, $x_{s}^{*}=x_{s} / L$ 
$\alpha(\omega)$ : Receptance of the first cantilever beam

$\alpha_{n}$ : Ratios of cantilever beam's $n$th natural frequency to its first natural frequency

$\beta(\omega)$ : Receptance of the second cantilever beam plus spring

$\beta_{1}$ : $\quad$ First mode coefficient of a single cantilever beam

$\omega: \quad$ PVA's natural frequency

$\omega_{i n}: \quad n$th natural frequency of $i$ th beam

$\omega_{f}$ : Fundamental frequency of the periodic excitation

$\omega_{i}: \quad$ Ratios of the $i$ th beam's first natural frequency to the fundamental frequency of the excitation

$\rho_{i}: \quad$ Density of $i$ th beam

$\mu$ : $\quad$ Mass ratio of the two beams

$\Phi_{n}: \quad n$th mode of a cantilever beam.

\section{Conflict of Interests}

The authors declare that there is no conflict of interests regarding the publication of this paper.

\section{Acknowledgment}

The authors are grateful to the National Science Council for its support of this research under the Grant no. NSC 98-2811E-011-001.

\section{References}

[1] J. Ormondroyd and J. P. den Hartog, "Theory of the dynamic vibration absorber," Transactions of the ASME, vol. 50, pp. 9-22, 1928.

[2] J. P. den Hartog, Mechanical Vibration, McGraw-Hill, New York, NY, USA, 1934.

[3] J. E. Brock, "A note on the damped vibration absorber," Journal of Applied Mechanics, vol. 68, p. A-284, 1946.

[4] M. B. Ozer and T. J. Royston, "Extending den Hartog's vibration absorber technique to multi-degree-of-freedom systems," ASME Journal of Vibration and Acoustics, vol. 127, no. 4, pp. 341350, 2005.

[5] M. B. Ozer and T. J. Royston, "Application of Sherman-Morrison matrix inversion formula to damped vibration absorbers attached to multi-degree of freedom systems," Journal of Sound and Vibration, vol. 283, no. 3-5, pp. 1235-1249, 2005.

[6] M. Z. Ren, "A variant design of the dynamic vibration absorber," Journal of Sound and Vibration, vol. 245, no. 4, pp. 762-770, 2001.

[7] W. O. Wong and Y. L. Cheung, "Optimal design of a damped dynamic vibration absorber for vibration control of structure excited by ground motion," Engineering Structures, vol. 30, no. 1, pp. 282-286, 2008.

[8] J. Q. Sun, M. R. Jolly, and M. A. Norris, "Passive, adaptive and active tuned vibration absorbers-a survey," ASME Journal of Mechanical Design, vol. 117, pp. 234-242, 1995.

[9] D. Chen and H. Xu, "Dynamic analysis of delayed damper system in engineering structures," Journal of Sound and Vibration, vol. 250, no. 4, pp. 609-616, 2002.
[10] R. A. Burdisso and J. D. Heilmann, "A new dual-reaction mass dynamic vibration absorber actuator for active vibration control," Journal of Sound and Vibration, vol. 214, no. 5, pp. 817$831,1998$.

[11] H. L. Sun, P. Q. Zhang, H. B. Chen, K. Zhang, and X. L. Gong, "Application of dynamic vibration absorbers in structural vibration control under multi-frequency harmonic excitations," Applied Acoustics, vol. 69, no. 12, pp. 1361-1367, 2008.

[12] S. G. Hill and S. D. Snyder, "Design of an adaptive vibration absorber to reduce electrical transformer structural vibration," ASME Journal of Vibration and Acoustics, vol. 124, no. 4, pp. 606-611, 2002.

[13] P. W. Wang and C. C. Cheng, "Design of vibration absorbers for structures subject to multiple-tonal excitations," ASME Journal of Vibration and Acoustics, vol. 128, no. 1, pp. 106-114, 2006.

[14] R. E. D. Bishop and D. C. Johnson, The Mechanics of Vibration, Cambridge University Press, Cambridge, UK, 1960.

[15] K. A. Lin and S. C. Huang, "Modeling and vibration analysis of spinning hard disk and head assembly," Journal of System Design and Dynamics, vol. 2, pp. 528-539, 2008. 

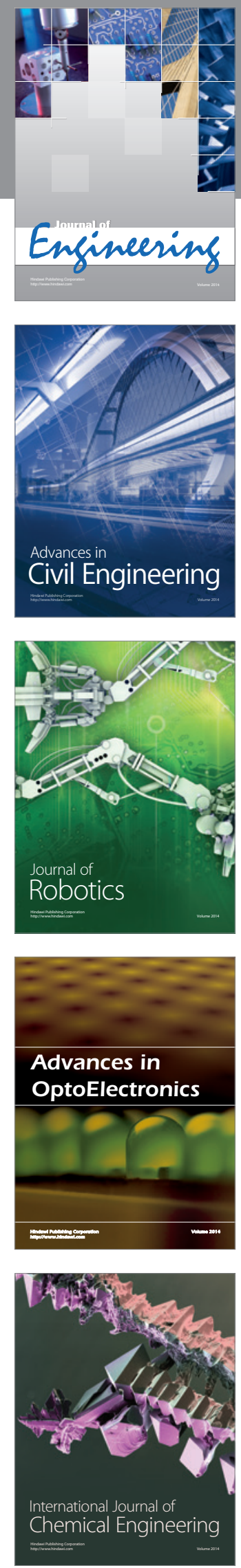

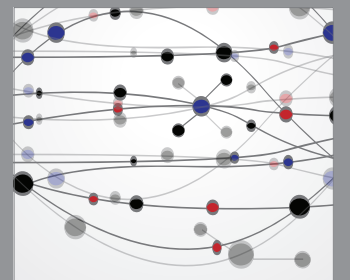

The Scientific World Journal
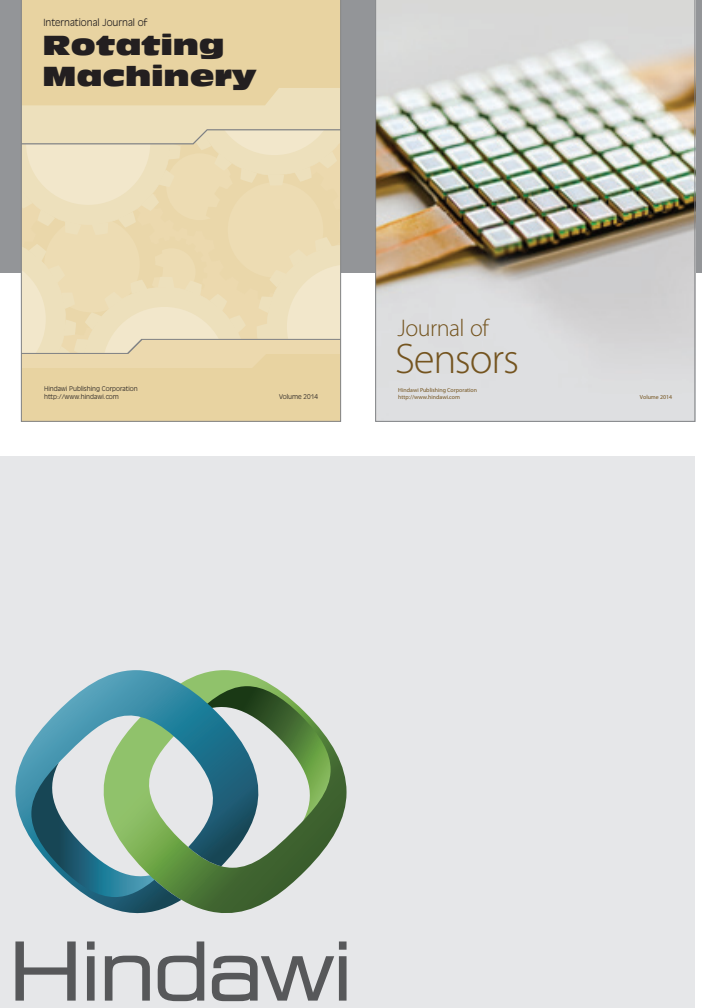

Submit your manuscripts at http://www.hindawi.com
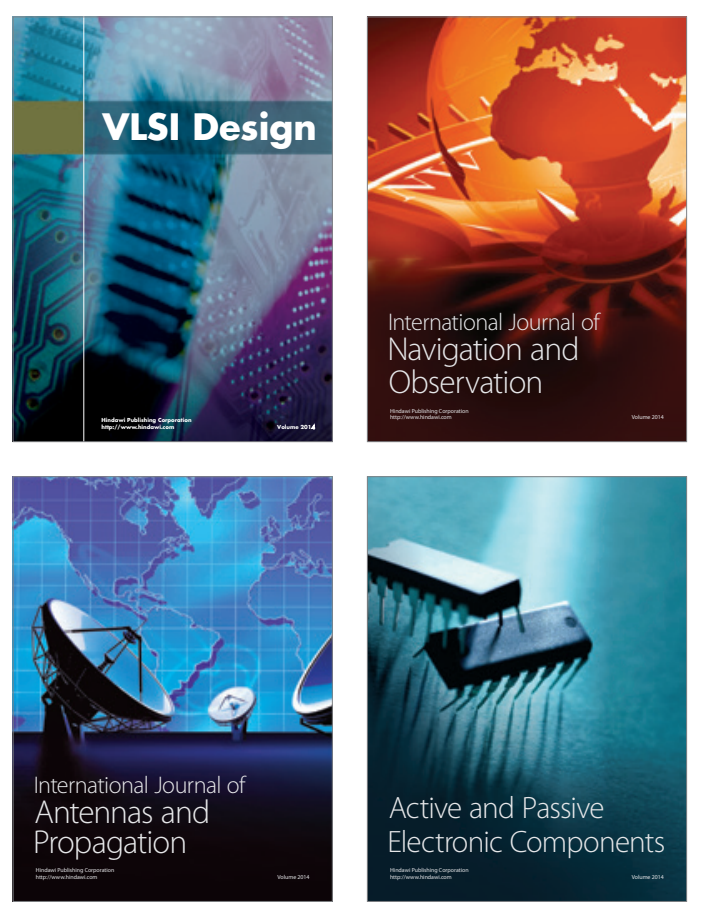
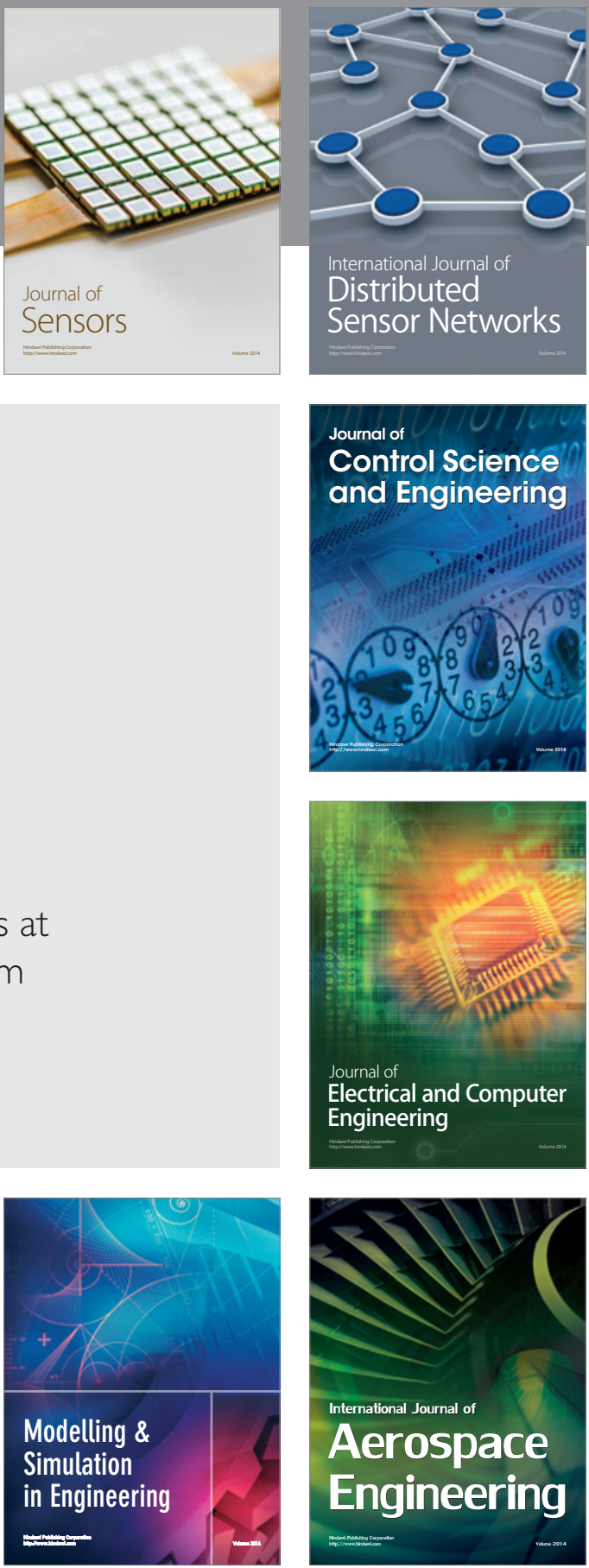

Journal of

Control Science

and Engineering
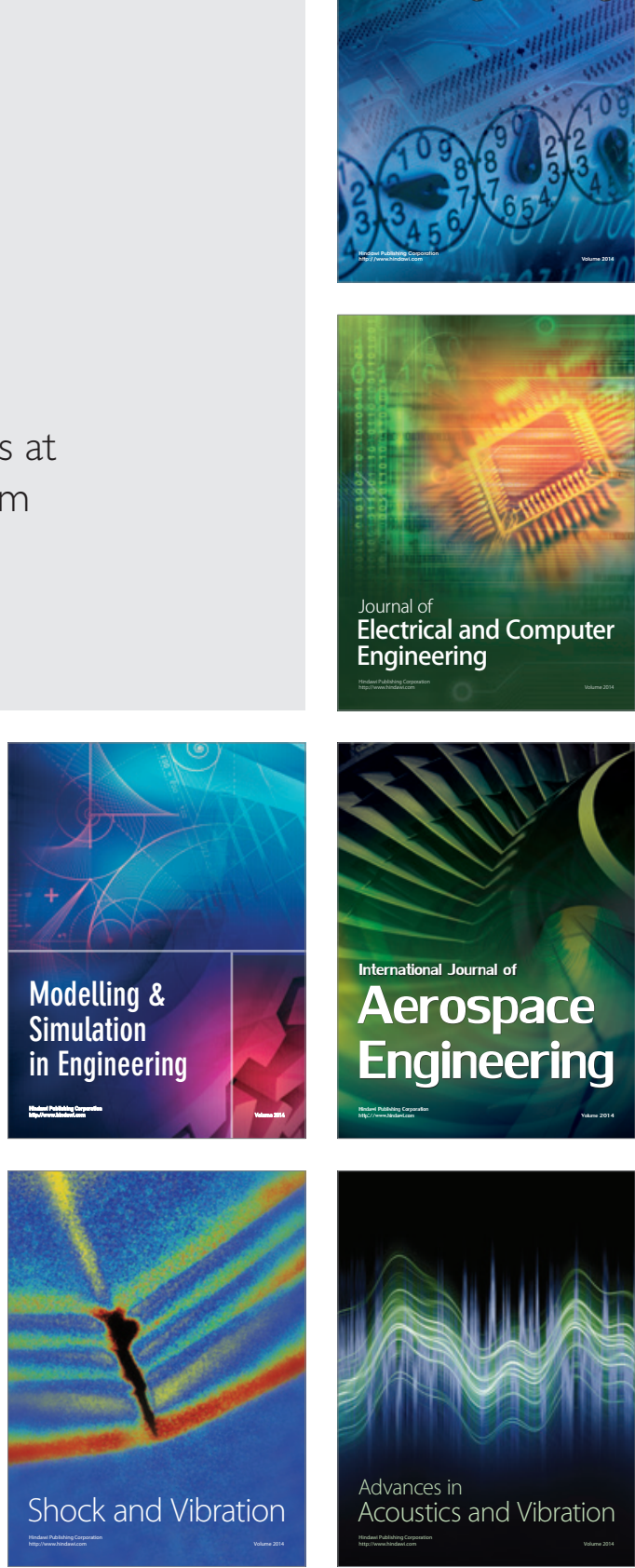